\title{
Bone health in Gambian women: impact and implications of rural-to-urban migration and the nutrition transition
}

\author{
S.E. Dalzell ${ }^{1}$, L.M.A. Jarjou ${ }^{2}$, A. Prentice ${ }^{1,2}$, K. Ward ${ }^{1}$ and G.R. Goldberg ${ }^{1,2}$ \\ ${ }^{1}$ Medical Research Council Elsie Widdowson Laboratory, Cambridge CB1 9NL, UK and \\ ${ }^{2}$ Medical Research Council Unit The Gambia, The Gambia
}

Urbanisation and the associated nutrition transition have been linked with the rapid and recent rise in osteoporotic fragility fracture incidence in many countries ${ }^{(1)}$. Predictions indicate that hip fracture incidence will increase 6-fold in Africa and Asia by 2050 , partially attributed to demographic transition and population ageing ${ }^{(2)}$. Differences in areal bone mineral density (aBMD) between rural and urban locations indicate that urban regions of high income countries (HIC) have lower aBMD and a higher incidence of hip fracture $^{(3)}$. The few studies conducted in low and middle income countries (LMIC) provide inconsistent results; in contrast to HIC, most have found higher aBMD in urban populations ${ }^{(4)}$.

In order to investigate the impact of migrating to an urban environment, we have conducted detailed studies of bone phenotype and factors affecting bone health in two groups of pre-menopausal Gambian women: urban migrant $(\mathrm{n}=58)$ and rural $(\mathrm{n}=81)$. Both groups spent their formative years in the same rural setting, urban women were known to have migrated when aged $\geq 16$ years. Bone phenotype (bone mineral content (BMC); bone area (BA); areal bone mineral density (aBMD), and size-adjusted BMC (height, weight and BA) of the whole-body, lumbar spine and hip) was measured by dual energy x-ray absorptiometry (DXA) with further characterisation of bone phenotype by peripheral quantitative CT (pQCT). Data were also collected on anthropometry, body composition, food and nutrient intakes, physical activity, socio-demographic characteristics, vitamin D status and $24 \mathrm{hr}$ urinary mineral outputs (Na, K, P and $\mathrm{Ca})$.

Mean age and height of rural and urban migrant groups were not significantly different $(\mathrm{p}>0 \cdot 05)$. Urban migrant women were significantly heavier $(\mathrm{p}<0.01)$. Significant differences in BMC and aBMD were found between groups at all skeletal sites, with urban women having higher BMC and aBMD; BA was not significantly different. The greatest difference in BMC was found at the lumbar spine $(8.5 \% \pm \mathrm{SE} 3 \cdot 0, \mathrm{p}<0.01)$. After adjusting for size, the differences between urban and rural spine BMC remained significant $(6 \cdot 2 \% \pm \mathrm{SE} 2 \cdot 1, \mathrm{p}<0 \cdot 01)$. These results indicate that rural-to-urban migration is associated with higher BMC, with differences mostly attenuated by adjusting for body size, particularly weight. In this African population, higher SA-BMC may affect future fracture risk.

\begin{tabular}{|c|c|c|c|c|c|c|c|}
\hline & \multicolumn{3}{|l|}{ Rural } & \multicolumn{3}{|c|}{ Urban Migrant } & \multirow[b]{2}{*}{$\mathrm{p}$} \\
\hline & Mean $^{\mathrm{a}}$ & $\mathrm{SD}^{\mathrm{b}}$ & $\overline{\mathrm{n}}$ & $\operatorname{Mean}^{\mathrm{a}}$ & $\mathrm{SD}^{\mathrm{b}}$ & $\mathrm{n}$ & \\
\hline$\overline{\operatorname{Age}(y)^{\mathrm{ab}}}$ & $43 \cdot 5$ & $41 \cdot 3,45 \cdot 5$ & 81 & 44.9 & $39 \cdot 5,47 \cdot 0$ & 58 & $\overline{0.3}$ \\
\hline Height (cm) & $160 \cdot 6$ & $5 \cdot 8$ & 81 & $162 \cdot 0$ & $6 \cdot 1$ & 58 & $0 \cdot 3$ \\
\hline Weight (kg) & $58 \cdot 3$ & $51 \cdot 6,67 \cdot 3$ & 81 & $67 \cdot 7$ & $55 \cdot 3,79 \cdot 4$ & 58 & $<0.001$ \\
\hline LS BMC (g) & $52 \cdot 77$ & 8.97 & 80 & $57 \cdot 18$ & $9 \cdot 18$ & 56 & $<0.01$ \\
\hline TB BMC (g) & 2116 & 244 & 81 & 2277 & 341 & 56 & $<0.01$ \\
\hline TH BMC (g) & $28 \cdot 16$ & 3.68 & 81 & $29 \cdot 87$ & $4 \cdot 07$ & 58 & $<0 \cdot 01$ \\
\hline
\end{tabular}

Acknowledgements

Supported by the UK Medical Research Council (MRC) under programmes U105960371 and U123261351. This research is jointly funded by the MRC and the Department for International Development (DFID) under the MRC/DFID Concordat agreement. SD is in receipt of an MRC $\mathrm{PhD}$ studentship.

1. Ballane G, Cauley JA, Luckey MM et al. (2014) J Bone Miner Res 29, 1745-1755.

2. Cooper C, Campion G, Melton LJ 3rd (1992) Osteoporos Int 2, 285-289.

3. Brennan SL, Pasco JA, Urquhart DM et al. (2010) J Epidemiol Community Health 64, 656-665.

4. Matsuzaki M, Pant R, Kulkarni B et al. (2015) PLoS One 10, e0132239. 